\title{
(2) OPEN ACCESS \\ Diamorphine for pain and distress in young patients: case examples and discussion of mechanisms
}

\section{Caradoc Morris}

Department of Inpatient Unit, Wigan \& Leigh Hospice, Hindley, UK

\section{Correspondence to}

Dr Caradoc Morris, Inpatient Unit, Wigan \& Leigh Hospice, Hindley, UK;

caradoc.morris1@nhs.net

Received 22 July 2021

Accepted 14 November 2021

\section{Check for updates}

(c) Author(s) (or their employer(s)) 2021. Re-use permitted under CC BY-NC. No commercial re-use. See rights and permissions. Published by BMJ.

To cite: Morris C. BMJ Supportive \& Palliative Care Epub ahead of print: [please include Day Month Year]. doi:10.1136/ bmjspcare-2021-003295

\section{ABSTRACT}

Diamorphine is a strong opioid licensed in the UK for many uses, including moderate and severe pain. In the early 2000s, its use in palliative medicine was widespread before a supply disruption led to preferential use of alternative, cheaper opioids. Though these supply issues were resolved, the use of diamorphine in palliative medicine has remained reduced, particularly with another UK supply disruption in 2021. Following anecdotal reports of good results from diamorphine use in younger patients, this piece discusses two cases of young patients with metastatic cancers suffering significant pain and psychological distress. Both patients were approaching end of life and required high doses of opioids, benzodiazepines and co-analgesics, all given to limited benefit. Both patients were rotated to diamorphine giving objective and subjective improvement in symptoms. These cases are presented in the context of newer information and description of the biochemical actions of diamorphine and its metabolites, which exert their own clinical effect before themselves generating active metabolites. Various trials on, and discussion about, diamorphine's unique metabolism and subsequent central nervous system effects help argue for its use in situations where extreme pain and psychological distress overlap.

\section{INTRODUCTION}

Diamorphine is a strong opioid licensed in the UK for moderate and severe pain. ${ }^{1}$ It has been 'extensively used in British medicine, and a wealth of experience has been accumulated'. ${ }^{2}$ The British National Formulary currently lists the indications for diamorphine use as acute pain, chronic pain not currently treated with a strong opioid analgesic, acute pulmonary oedema and myocardial infarction. ${ }^{3} \mathrm{~A}$ review of the Cochrane Library also yields many trials using diamorphine for labour pain, sickle cell disease pain or postoperative pain.

In the early 2000s, its use in palliative medicine was widespread. A 2001 survey of $165 \mathrm{UK}$ and Ireland palliative care inpatient units found that all of the UK units surveyed used diamorphine in their continuous subcutaneous infusions (CSCIs or 'syringe drivers'), usually in combination with other commonly used end of life medications. ${ }^{4}$ A 2006 survey of UK centres also found that diamorphine was used in at least 157 of 328 CSCIs, among the most common drug combinations. ${ }^{5}$ And even more recently, in 2017, a Bedfordshire community service showed that $85 \%$ of 392 community patients assessed over a 1-year period had subcutaneous diamorphine prescribed at end of life. $^{6}$

However, following a supply disruption in 2004, recommendations were made to conserve UK supplies of diamorphine by using alternative opioids where possible. ${ }^{2}$ Though these supply issues were ultimately resolved, the use of diamorphine in palliative medicine remained reduced, particularly with the introduction of cheaper alternatives such as subcutaneous oxycodone in 2001. ${ }^{5}$ A national survey of 2000 CSCIs across 35 UK centres in 2014 showed the most commonly prescribed opioid was morphine (28\%), followed by oxycodone and alfentanil, then diamorphine. $^{7}$ In mid-2021, another shortage of diamorphine solution for injection has been announced in the UK which will likely further affect its use. ${ }^{8}$

Anecdotally, use of diamorphine among the author's peers within palliative medicine is mixed. Longer serving practitioners still occasionally recommend or use diamorphine in opioid rotation for poorly controlled pain. These clinicians feel a particular benefit for younger patients. More junior practitioners are less 
experienced using diamorphine and thus less inclined to prescribe it. All are bound by local and regional guidelines which recommend the use of cheaper and more familiar opioids as first line.

This article presents two cases of young people under 30 with rapid progression of metastatic cancers. Both had a relatively short time from initial diagnosis to death, and during that time struggled significantly with increasing and poorly controlled pain, as well as psychological and emotional distress. Both were admitted to the hospice within the last weeks of their lives for support with pain control, following unsuccessful trials of increasing and rotated opioids in other settings. Neither had any significant renal or hepatic dysfunction.

Both patients were rotated from oxycodone to diamorphine as inpatients, which led to subjective improvement in their pain and psychological symptoms, and an objective decrease in their distress and breakthrough medication use. Other medications could also be slightly reduced. In one case, the response was so profound that the use of naloxone was required for reversal of effects.

Newer findings in the pharmacology of diamorphine advocate its consideration in trials of opioid rotation for those suffering with combined pain and psychological distress. This may be particularly relevant for newer practitioners who are less familiar with its use.

\section{CASE EXAMPLES}

\section{Case A}

Case A had gradually escalating pain through his disease course and was admitted to the hospice with medicines through a CSCI. At its peak (Day 2 admission), the CSCI prescription comprised $80 \mathrm{mg}$ oxycodone, $15 \mathrm{mg}$ midazolam and $400 \mathrm{mg}$ ketamine. In the same 24-hour period, the patient used as breakthrough medication $9 \times 10 \mathrm{mg}$ SC oxycodone, $3 \times 200 \mu \mathrm{g}$ fentanyl lozenge (Actiq), $5 \times 2.5 \mathrm{mg}$ SC midazolam and $4 \times 6.25 \mathrm{mg}$ SC levomepromazine (initially for nausea).

The following day (Day 3 admission) an opioid rotation was performed. This also incorporated a dose increase to help improve symptoms. The CSCI prescription was altered to $120 \mathrm{mg}$ diamorphine, 30 mg midazolam, $300 \mathrm{mg}$ ketamine and $25 \mathrm{mg}$ levomepromazine. However, within 24 hours, the patient was noted to have a respiratory rate of 4-6 breaths/min, requiring naloxone rescue. The CSCI prescription was subsequently reduced (into Day 4 admission) to $90 \mathrm{mg}$ diamorphine (comparable to the original oxycodone dose), $20 \mathrm{mg}$ midazolam, $300 \mathrm{mg}$ ketamine and 12.5 mg levomepromazine. Given the immediate response to naloxone, this respiratory depression was felt to be related to opioid dose rather than benzodiazepine dose.

Despite this, further use of naloxone rescue was required, again based on the patient's respiratory rate. He was arouseable and reported an improvement in his pain and psychological symptoms, but clinical concerns superseded. Ahead of a planned coeliac plexus block (CPB) on Day 6 admission, the opioid dose in the CSCI was intentionally significantly reduced to 30 $\mathrm{mg}$ diamorphine to allow a washout period following the episodes of respiratory depression and to pre-empt any opioid sparing following the $\mathrm{CPB}$.

Of note to the team was the patient's reported improvement in symptoms of pain and distress, increased sedation notwithstanding, following the rotation to diamorphine. This response persisted through dose reductions, including the overall reduction from $80 \mathrm{mg}$ oxycodone to $30 \mathrm{mg}$ diamorphine (equivalent to $30 \mathrm{mg}$ oxycodone). Opioid-induced hyperalgesia $(\mathrm{OIH})$ could be a consideration, but would not be in keeping with the previous gradual increase in opioids to which he responded, nor his reported pain improvement at higher doses of diamorphine (though accompanied by sedation).

The improved response to diamorphine continued after the CPB, which improved but unfortunately did not resolve his pain. This response was supported by objective observations from his family who noticed he was more 'relaxed', 'settled' and 'comfortable' between breakthrough doses. Nursing staff also observed that they could use breakthrough doses less frequently and of diamorphine alone rather than the oxycodone/midazolam combinations used previously, usually achieving an equal or improved response.

\section{Case B}

Case B also had significant pain and psychological distress, though her pain had been poorly controlled for longer. Numerous changes to her CSCI in the month prior to admission give an important background to the consideration of the effect of diamorphine here. Maximum doses of medications in the CSCI at any time included $200 \mathrm{mg}$ oxycodone, $75 \mathrm{mg}$ levomepromazine and $400 \mathrm{mg}$ ketamine. A nerve block had also been performed less than 3 weeks before admission with minimal benefit. The patient was admitted to the hospice in extremis. The $200 \mathrm{mg}$ oxycodone dose in the CSCI had recently been reduced (due to concurrent medical issues) to $35 \mathrm{mg}$ oxycodone, with $10 \mathrm{mg}$ midazolam and $6.25 \mathrm{mg}$ levomepromazine. The ketamine dose had already been removed. No changes were made initially to allow for a period of assessment, and some success was achieved with psychological support. However, in the first 24 hours breakthrough medications included $10 \times 5 \mathrm{mg}$ SC oxycodone, $7 \times 2.5$ $\mathrm{mg}$ midazolam and $1 \times 100 \mu \mathrm{g}$ sublingual fentanyl (Abstral). Increasing the doses of breakthrough medications to $10 \mathrm{mg}$ SC oxycodone and $5 \mathrm{mg}$ SC midazolam gave no extra relief.

On Day 4 admission, an opioid rotation was performed from $35 \mathrm{mg}$ oxycodone to $40 \mathrm{mg}$ diamorphine. The CSCI also contained $15 \mathrm{mg}$ midazolam and $6.25 \mathrm{mg}$ levomepromazine, which remained 
unchanged. With some reported benefit from the patient, the CSCI was increased again on Day 5 admission (to $60 \mathrm{mg}$ diamorphine, $25 \mathrm{mg}$ midazolam and $6.25 \mathrm{mg}$ levomepromazine) and Day 7 admission (to $120 \mathrm{mg}$ diamorphine, $30 \mathrm{~g}$ midazolam and $6.25 \mathrm{mg}$ levomepromazine). Objectively, symptoms of distress appeared to reduce as the diamorphine was increased, meaning the midazolam dose was not significantly changed. The Day 7 CSCI prescription was the final prescription up to the patient's discharge home on Day 12 for terminal care.

There is an important distinction in Case B from Case $\mathrm{A}$, in that following the rotation from oxycodone to diamorphine, the dose in the CSCI was substantially increased (from $35 \mathrm{mg}$ oxycodone to $120 \mathrm{mg}$ diamorphine). However, both the patient and her relatives observed a notable improvement in her general comfort and reported symptoms beginning with the opioid rotation and continuing with its increase. Much like in Case A, nursing staff found an improved response from diamorphine breakthrough doses alone, compared with the oxycodone/midazolam combinations used prior. The final CSCI dose of $120 \mathrm{mg}$ diamorphine is importantly still less than the previous maximum opioid dose in the pre-admission CSCI of $200 \mathrm{mg}$ oxycodone.

As mentioned, the Day 7 CSCI prescription was the final prescription up to the patient's discharge home on Day 12 for terminal care. This was $120 \mathrm{mg}$ diamorphine, $30 \mathrm{~g}$ midazolam and $6.25 \mathrm{mg}$ levomepromazine. In those final days of admission, fewer breakthrough medication doses were used.

\section{DISCUSSION}

Diamorphine is a strong opioid with a higher potency than morphine, meaning a smaller dose is needed to achieve a comparable effect. ${ }^{9}$ After administration, diamorphine is metabolised to 6-monoacetylmorphine (6-MAM) and then to morphine, both of which are active metabolites. ${ }^{9-11}$ Morphine itself is then metabolised to the active morphine-6-glucaronide (M6G) and the inactive morphine-3-glucaronide. ${ }^{11}$

Diamorphine is metabolised by carboxylesterase and cholinesterase enzymes found in the liver, but also in blood and other organs. ${ }^{9}{ }^{12}$ As such, hepatic impairment would not significantly affect diamorphine metabolism. ${ }^{12}$ Though diamorphine is able to cross the blood-brain barrier (BBB), its peripheral metabolism is rapid and so little is metabolised centrally. ${ }^{913}$ As such, the central actions of 6-MAM and morphine, rather than diamorphine as a prodrug, are thought to be responsible for any clinical effects seen. ${ }^{9} 12$ 13 6 -MAM also crosses the BBB more readily than morphine. ${ }^{11} 13$

6-MAM and morphine are both agonists for the mu-opioid receptor with similar affinity, however, 6-MAM is thought to have a higher intrinsic activity than morphine. ${ }^{9-11} 13$ Furthermore, Andersen et al showed in 2009 that an in vivo opioid antagonist blocked the analgesic effect of diamorphine/6-MAM but not of morphine, suggesting the two may act at a different binding site or receptor subtype. ${ }^{11}$

A trial in 2001 was cautious in saying that 'inferring intrinsic efficacy directly from potency measurements can be misleading', acknowledging that variables such as receptor affinity and receptor subtypes should be taken into account. ${ }^{10}$ But the findings of different levels of activity and variable antagonism raise the possibility of different biochemical actions and subsequent clinical effects of 6-MAM and morphine. This could suggest a unique role of diamorphine (as the prodrug to 6-MAM and morphine) compared with other opioids.

Opioids act on mu-opioid receptors to stimulate a 'reward' effect, caused by the excitation of dopaminergic neurons and subsequent dopamine release. ${ }^{913}{ }^{14}$ Variations in dopamine release have been noted between 6-MAM and morphine. Gottås et al's study in rats showed that 6-MAM gave a rapid initial rise in dopamine with bolus injection. As this tapered, a second slower rise was seen, thought to be related to rising concentrations of morphine from 6-MAM metabolism. ${ }^{13}$ This further supports the two metabolites as distinctly acting compounds and, as the rate of change of dopamine levels is more associated with the 'reward' or 'euphoria' sensation, ${ }^{13}$ that they can exhibit different clinical effects. This would be significant when administering diamorphine as a breakthrough medication as with Cases A and B, and may explain the observations that diamorphine could be administered to good effect in isolation without being augmented by a benzodiazepine for concurrent distress.

As a result of these overlapping biochemical processes, the use of diamorphine in poorly controlled symptoms of pain or distress can become more complex. The metabolism of diamorphine to two active substances (and its continued metabolism if delivered in a CSCI) could create a competition effect; Gottås postulated that 'the competitive binding to receptors between morphine and 6-MAM would likely influence and modulate the dopamine response depending on the concentration ratios in the ECF'. Furthermore, benzodiazepines and tricyclic antidepressants (both commonly used in Palliative Medicine) can reduce the glucuronidation of morphine to the active M6G, affecting the comparative levels of the two. ${ }^{12}$

The degree to which these interactions occur and the subsequent balance of active metabolites achieved would vary from patient to patient, and would explain the range of clinical responses observed across a population if different levels are achieved between individuals. It would be reasonable to assume that in Cases A and B the comparative ratios of metabolites and concurrent medications were right to give such a positive clinical response. Though unpredictable, the principle highlights diamorphine as a consideration in 
poorly controlled pain and distress with the potential for good effect.

The identification of 6-MAM as an active compound and its potential for slightly different mechanisms of action from morphine, particularly in relation to dopamine release, may contribute to anxiolytic effects clinically. Case A shows an example of an analgesic response to diamorphine strong enough to require reducing the total opioid dose, but also with a reduction in benzodiazepine use suggesting some anxiolytic benefit for this patient from diamorphine specifically. In Case B, although the total benzodiazepine dose used in a 24-hour period was variable, the frequency of administration clearly reduced, suggesting an improvement in symptoms of distress.

Combining multiple biochemical actions of diamorphine with genetic variations in opioid receptor subtypes and variations in the expression of esterase enzymes metabolising diamorphine, it is clear that inter-individual response to diamorphine varies. This represents a limitation in this case report, as the clear responses of these two patients of rotation to diamorphine will not necessarily be applicable to a wider population with different disease states and concurrent medications. Further limitations are the report of only two patients, and that the response to diamorphine and pattern of change between the two was not comparable. A rapidly deteriorating disease trajectory could have acted as a confounder, as could the supportive environment of the hospice. However, the responses reported by both patients immediately following opioid rotation would go slightly against the latter. Both patients reported a subjective improvement in their symptoms and this was supported by their families. However, these improvements were not quantified using an assessment tool such as IPOS (Integrated Palliative Care Outcome Scale), VAS (Visual Analogue Scale) or PCOS (Palliative Care Outcome Scale) and titrations were instead made from an overall clinical assessment.

OIH could be a consideration for both patients, though seemed unlikely. Historically neither patient had reported worsening pain from increasing background doses of opioids, or from the use of breakthrough doses. In fact, opioid rotations were considered due to minimal benefit rather than a worsening of symptoms. Other recognised symptoms of OIH such as hyperalgesia, allodynia and more diffusely spread pain ${ }^{15}$ were not reported.

There were some notable similarities between the two patients. Both were young with a heavy burden of oncological disease, and a limited response to increasing doses of opioids. Both had been rotated through at least one alternative opioid with no significant benefit. Both were struggling with significant psychological distress from their conditions, and this was something that seemed to improve with the use of diamorphine, evidenced by external observations and a decreased need for benzodiazepine use.

\section{CONCLUSION}

Rather than promoting a more widespread use of diamorphine, this piece aims to advocate its consideration in situations where one or two opioids have had only mild effect, particularly at high doses, and where concurrent psychological distress is a compounding factor. Oral morphine is still recommended as first line in palliative care for patients requiring strong opioids. ${ }^{16} 17$ Diamorphine still exists as an effective alternative for patients suffering with severe pain and psychological distress.

Funding The authors have not declared a specific grant for this research from any funding agency in the public, commercial or not-for-profit sectors.

Competing interests None declared.

Patient consent for publication Not applicable.

Provenance and peer review Not commissioned; internally peer reviewed.

Open access This is an open access article distributed in accordance with the Creative Commons Attribution Non Commercial (CC BY-NC 4.0) license, which permits others to distribute, remix, adapt, build upon this work noncommercially, and license their derivative works on different terms, provided the original work is properly cited, appropriate credit is given, any changes made indicated, and the use is noncommercial. See: http://creativecommons.org/licenses/by-nc/4. $0 /$.

ORCID iD

Caradoc Morris http://orcid.org/0000-0003-4632-6121

\section{REFERENCES}

1 Twycross R, Wilcock A, Howard P. Palliative care formulary. 387. 6th edn. London, UK: Pharmaceutical Press, 2019.

2 Clark C. Diamorphine: the return of an old friend. Hospital pharmacy Europe, 2009. Available: https://hospitalpharmacy europe.com/news/editors-pick/diamorphine-the-return-of-anold-friend [Accessed 15 Jul 2021].

3 Joint Formulary Committee. British National Formulary (online). London, UK: BMJ Group and Pharmaceutical Press, 2021. http://www.medicinescomplete.com

4 O'Doherty CA, Hall EJ, Schofield L, et al. Drugs and syringe drivers: a survey of adult specialist palliative care practice in the United Kingdom and Eire. Palliat Med 2001;15:149-54.

5 Wilcock A, Jacob JK, Charlesworth S, et al. Drugs given by a syringe driver: a prospective multicentre survey of palliative care services in the UK. Palliat Med 2006;20:661-4.

6 Marvin R, Grove S, Spathis A, et al. P-42 injectable medication at the end of life: a common task for generalist community clinicians. BMJ Support Palliat Care 2017;7:A15.3-16.

7 Dickman A. Identification of the most commonly prescribed opioid for administration by continuous subcutaneous infusion. BMJ Support Palliat Care 2014;4:A109.1-A109.

8 Specialist Pharmacy Service. Shortage of diamorphine injection 5 and 10mg, 2021. Available: https://www.sps.nhs.uk/articles/ shortage-of-diamorphine-5-and-10mg [Accessed 20 Jul 2021].

9 Boix F, Andersen JM, Mørland J. Pharmacokinetic modeling of subcutaneous heroin and its metabolites in blood and brain of mice. Addict Biol 2013;18:1-7.

10 Selley DE, Cao CC, Sexton T, et al. Mu opioid receptormediated G-protein activation by heroin metabolites: 
evidence for greater efficacy of 6-monoacetylmorphine compared with morphine. Biochem Pharmacol 2001;62:447-55.

11 Andersen JM, Ripel A, Boix F, et al. Increased locomotor activity induced by heroin in mice: pharmacokinetic demonstration of heroin acting as a prodrug for the mediator 6-monoacetylmorphine in vivo. J Pharmacol Exp Ther 2009;331:153-61.

12 Rook EJ, Huitema ADR, van den Brink W, et al. Pharmacokinetics and pharmacokinetic variability of heroin and its metabolites: review of the literature. Curr Clin Pharmacol 2006;1:109-18.

13 Gottås A, Boix F, Øiestad EL, et al. Role of 6-monoacetylmorphine in the acute release of striatal dopamine induced by intravenous heroin. Int J Neuropsychopharmacol 2014;17:1357-65.

14 Johnson SW, North RA. Opioids excite dopamine neurons by hyperpolarization of local interneurons. J Neurosci 1992;12:483-8.

15 Twycross R, Wilcock A, Howard P. Palliative care formulary. 368. 6th edn. London, UK: Pharmaceutical Press, 2019.

16 Taubert M, Ross JR, Prettyjohns M, et al. Opioids in palliative care: is the new NICE guideline relevant to specialist palliative care providers? BMJ Support Palliat Care 2012;2:209-12.

17 National Institute for Health and Care Excellence. Palliative care for adults: strong opioids for pain relief (CG140), 2012. Available: https://www.nice.org.uk/guidance/cg140 [Accessed 08 Feb 2021]. 